\title{
LYOCELL FABRIC DYED WITH NATURAL DYE EXTRACTED FROM MARIGOLD FLOWER USING METALLIC SALTS
}

\author{
Sayed Yaseen Rashdi ${ }^{1}$, Tayyab Naveed ${ }^{2,3}$, Noor Sanbhal ${ }^{4}$, Sikandar Almani ${ }^{5}$, Peng Lin ${ }^{1}$, Wang Wei ${ }^{1,6, *}$ \\ 1 College of Chemical Engineering, Donghua University, Shanghai 201620, China \\ 2 College of Textiles, Donghua University, Shanghai 201620, China \\ 3 Department of Textile Engineering and Technology, University of the Punjab, Lahore 54590, Pakistan \\ 4 Depatment of Textile Engineering, Mehran University of Engineering and Technology, Jamshoro, Sindh 76062, Pakistan \\ 5 GEPEA Lab - UMR 6144 CNRS, Université de Nantes, CRTT - 37, bd de l'Université, BP 406, 44602 Saint-Nazaire Cedex, France \\ 6Saintyear Holding Group Co., Ltd., Xiaoshan, Hangzhou 311221, Zhejiang, China \\ E-mail: wangv@dhu.edu.cn
}

\begin{abstract}
:
The application of natural dyes is increasing each year due to their environmental friendliness and easy application on cellulose fibers. In this study, the natural dye from the Mexican marigold flower was extracted using a Soxhlet extraction apparatus. The extracted natural dye was applied on lyocell fabric with five different metallic salts using pre-mordanting and post-mordanting methods. It was observed that different color shade depth was achieved with different fixing agents. The color shade depth (K/S) washing fastness, light fastness, rubbing fastness, perspiration, and Fourier transform infrared (FTIR) test results of all dyed samples were excellent in both pre-and post-mordanting methods. There was no significant difference in the results between post- and pre-mordanting fixation methods. However, the results showed that mordant ferrous sulfate had higher K/S value as compared to all other mordants. The dye extracted from marigold flower showed good dyeing efficiency with mordant to excellent colorfastness tests. FTIR results showed that there was no structural change in lyocell fabrics, before and after dyeing processes. Thus, a natural dye extracted from marigold flower has shown good colorfastness properties without damaging its fiber structure.
\end{abstract}

\section{Keywords:}

Lyocell fabric, natural dyes, marigold flower, mordanting, dye extraction

\section{Introduction}

In recent years, the coloring of textile materials with the dyes obtained from plants and other natural resources has attained excessive consideration [1, 2] due to their low allergic reactions and environmental -friendliness [2, 3]. In addition, natural dyes are safe, unlike synthetic dyes are nonbiodegradable and may have harmful effect on the health of living beings [4].

The invention of synthetic dyes in 1856 by W.H Perkin came up with an alternative to the natural dyes with more refined and uniform results [5]. Synthetic dyes are inexpensive due to its unlimited production. The application of synthetic dyes is increased in the number of the fields such as food [6], cosmetics [7], photodynamics [8], nonlinear optical activity, [9] and more significantly in the textile industries [10, 11] due to ease in dyeing. However, toxicity and non-eco-friendly are the main drawbacks of the synthetic dyes which limit its application [4]. Therefore, many countries and organizations have imposed control and check on the production of synthetic dyes such as the European Economic Community, the United States, Germany, etc. [12, 13].

Nature has gifted us with more than 500 dye-yielding plants [14]. The art of dyeing with the natural colorants was one of the ancient practices by the Europeans in the era of the Bronze Age. Some of the well-recorded ancient dyes include the following: madder, a red dye obtained from the roots of Rubia tinctorium, blue indigo from the leaves of Indiogofera Tinctoria, and yellow from the stigma of the saffron plant (Crocus sativus $\mathrm{L}$ ). Moreover, the most famous and high-valued color over the centuries was noticed in the stretch of the Bible as the train purple, a dye obtained from the spiny dye, murex shellfish [15]. One such dye-yielding plant species, Tagetes erecta L. marigold flower ( $T$. erecta Linn), is an herbaceous plant of sunflower family (Asteraceae). It is mostly cultivated in the warm temperature in northern Europe as a garden flower that is one of the natural sources for obtaining yellow color. They are also grown for colorant production in Mexico, Peru, Ecuador, Spain, India, and China. The color of the flower ranges differently from yellow-gold to orange-red and mahogany (reddish-brown). Marigold flower plants are stout and grown to the height of 1-3 feet with 0.5 feet spread. The length of the leaf is less than 2 inches and tint is green in color [16]. Among all natural plants, marigold flowers have the highest concentration of lutein (zeaxanthin). Thus, lutein concentration in the marigold flower measures the strength of the natural dye [17].

Currently, the application of natural dyes is increasing worldwide, as they are environment-friendly [18, 19]. The 
natural dyes may have poor affinity and inferior colorfastness for the textile goods without fixing agents. Consequently, mordanting agents also called metallic salts are additionally applied which improves the properties of natural dyes on fiber and fabrics [20]. In other words, the mordanting agents assist in the absorption and fixation of dye between the fibers. Many mordanting agents, such as ferrous sulfate, copper sulfate, potash alum, potash dichromate alum, and stannous chloride, have been applied in dyeing [21].

Previously, cotton woven fabric has been dyed with natural dyes extracted from marigold flower [22]. However, the lyocell is a natural, manmade regenerated cellulosic fiber which is obtained from wood pulp. It is an excellent ecological fabric that represents a landmark in the development of environmentally sustainable textiles [23-25]. In our previous work, we dyed lyocell fabric with natural dye extracted from pomegranate peel [26] and obtained good colorfastness properties.

In this research study, the natural dye extracted from the petals of Mexican marigold flower was applied to the lyocell fabric with five different mordanting agents. The effects of various mordanting agents of the dye on lyocell fabric were investigated and color shades were analyzed. Color strength of naturally dyed lyocell fabrics was investigated using spectrophotometer. The difference in color shades, $L^{*}, a^{*}, b^{*}, c^{*}$, and $h^{*}$ values, was calculated and compared with shades obtained by different mordanting agents. However, lyocell fabric dyed with marigold natural dye and used ferrous sulfate as a fixing agent showed superior dyeing properties.

\section{Materials and methods}

Mexican marigold flowers were procured from the domestic market of Shanghai, China. 100\% lyocell fabric white (pretreated) was obtained from the Hangzhou Xin Sheng Dyeing \& printing Company LTD. Metallic salts (mordanting agents), such as potash alum, potash dichromate, copper sulfate, stannous chloride, and ferrous sulfate, were analytical grade chemicals. Moreover, ethanol, sodium hydroxide, formic acid, and L-histidine hydrochloride $\left(\mathrm{C}_{6} \mathrm{H}_{902} \mathrm{~N}_{3} \cdot \mathrm{HCl} . \mathrm{H}_{20}\right)$ were used for conducting the tests.

\subsection{Preparation of raw material}

Water bath shaking machine was used for dyeing lyocell fabrics, and Soxhlet apparatus was selected to extract the natural dye. First, petals were removed from Mexican marigold flower. These petals were washed with water to remove the dust particles and other impurities. The petals were dried in the daylight for 48 hours. After drying, the dried petals were crushed into the fine particles (powder) with the help of grinder machine. The extracted dye in powder form was used for the further process. Figure 1 shows the preparation steps of the raw material.

\subsection{Soxhlet extraction method}

A Soxhlet extractor Franz Von Soxhlet [27] was used for filtration of the solvent and residue to achieve better and efficient separation. An organic solvent (ethanol) was also used during the extraction method. The evaluated amount of marigold powder (F) and dignified volume solvent (S) were taken in a certain F/S ratio. The raw material (grinded powder of flower) was kept in the thimble of Soxhlet extractor and a condenser was filled with a high flow rate of water over it. The extraction was carried out for 6 hours continuously. The volume of the solution attained was measured. Furthermore, a rotatory evaporator was used for the evaporation of the solvent and the dye extracted was weighed [28]. Figure 2 shows the mechanism of the Soxhlet extraction method.

The dried Mexican marigold flower powder $(10 \mathrm{~g})$ was taken in the thimble of an apparatus. In a round bottom flask, the ethanol $(240 \mathrm{ml})$ and distilled water $(160 \mathrm{ml})$ with liquor ratio of $1: 40$ were heated at a temperature of $95^{\circ} \mathrm{C}$. The vapors were passed through the tube and elevated into the condenser. At the top, the vapors were condensed and dripped down into the thimble. The thimble was shattered by the suction effect when the condensed solvent was grasped at the top of the siphon. The extracted material winged back into the round bottom flask and started mixing with the clean solvent. The extracted dye was purified through the rotatory evaporator and the filtered dye solution was used for dyeing thelyocell fabric samples. It was observed that the tint of the dye extracted was dark orange in color [29].

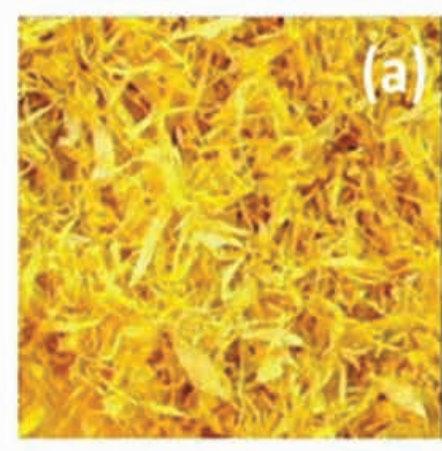

(a) Petals in cut form

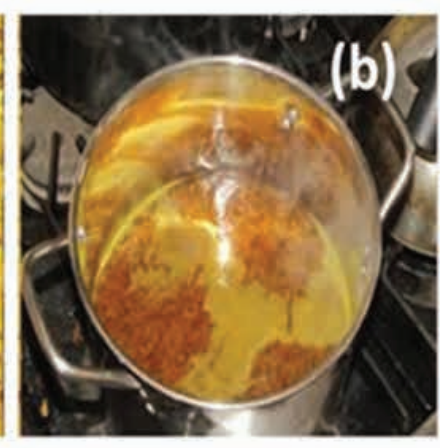

(b) Washing of petals

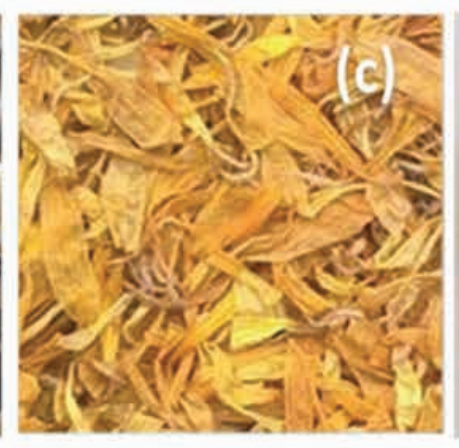

(c) Dried petals in sunlight

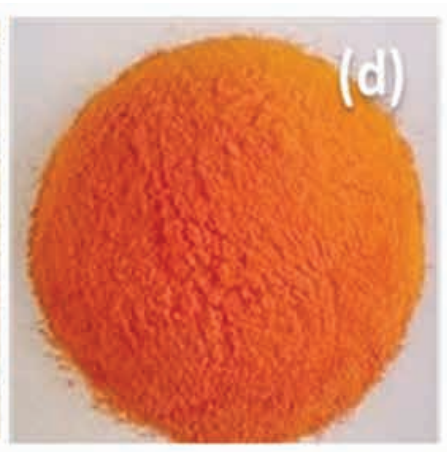

(d) Powder of petals

Figure 1. Preparation steps of the for raw material. 


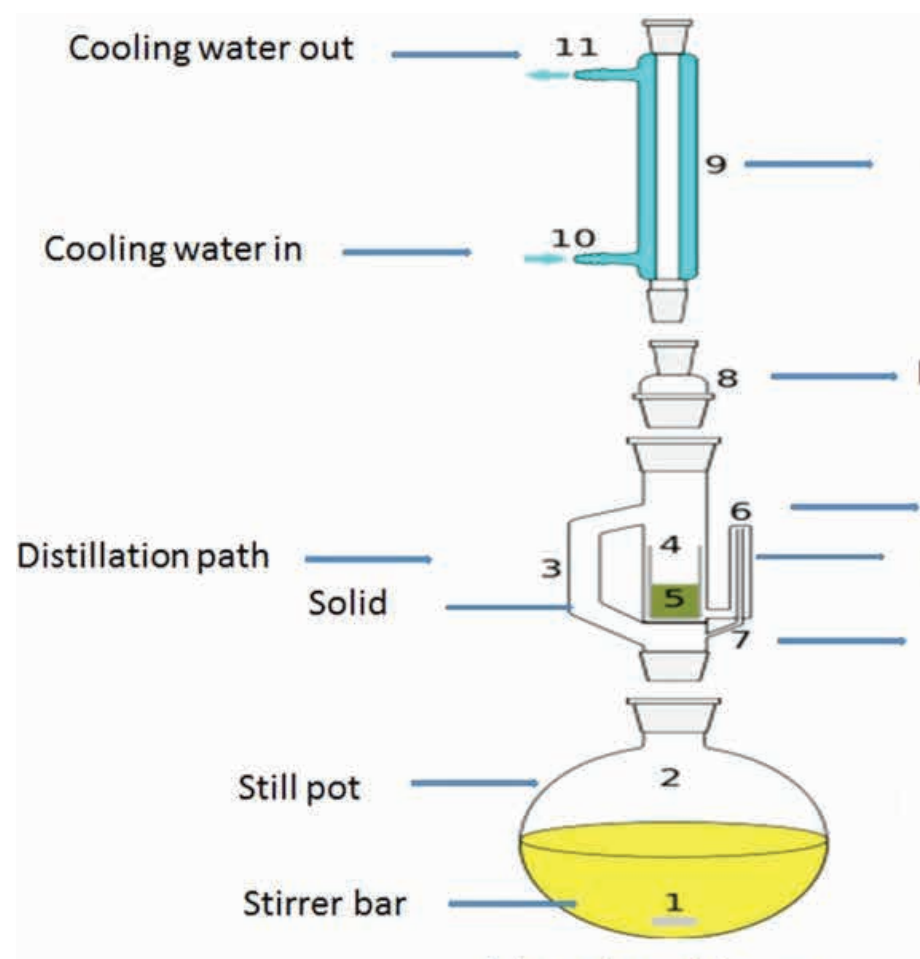

(a). Technical diagram
Condenser

Expansion adapter

Siphon top

\section{Thimble}

Siphon exit

\section{Results and discussion}

\subsection{Coloring effect of extracted dye and mordants}

The dark orange extract was obtained from the flowers of marigold. This extracted dye was applied to the lyocell fabrics using five different mordanting agents, stannous chloride $\left(\mathrm{SnCl}_{2}\right)$, potash alum $\left(\mathrm{KAl}\left(\mathrm{SO}_{4}\right)_{2} 12 . \mathrm{H}_{2} \mathrm{O}\right)$, ferrous sulfate $\left(\mathrm{FeSO}_{4}\right)$, potash dichromate $\left(\mathrm{Kr}_{2} \mathrm{Cr}_{2} \mathrm{O}_{7}\right)$, and copper sulfate $\left(\mathrm{CuSO}_{4}\right)$, by pre-mordanting and post-mordanting dyeing methods. The color shades obtained on the fabric samples were found different for each mordanting. Some of the mordanting agents have light penetration and better color strength as compared to the other agents.

Table 1 shows the coloring effect on dyed lyocell fabric samples using five different mordanting agents in pre-mordanting and post-mordanting methods at the same temperature of $90^{\circ} \mathrm{C}$. Data color, SF-600 was used to measure the dye captivation concentration on the shallow of lyocell fabric. In addition, the ranges of color were also found different on lyocell fabric samples using $L^{*}, a^{*}, b^{*}, C^{*}$, and $h$ values [30]. Table 2 shows the CIE Lab $\left(L^{*}, a^{*}, b^{*}, C^{*}\right.$, and $\left.h^{*}\right)$ values of dyed lyocell fabric samples at $90^{\circ} \mathrm{C}$. It is observed that the color shade values of lyocell fabrics with mordanting agent ferrous sulfate is higher in both mordanting methods as compared to the other mordanting agents used for dyeing. The highest color value $(\mathrm{K} / \mathrm{S}=7.812)$ was found with ferrous sulfate in post-mordanting method, whereas the lowest color value $(\mathrm{K} / \mathrm{S}=0.247)$ was found with potash alum.

The optimum results of dyeing lyocell fabric were achieved at acetic $\mathrm{pH}$ 4-6 using five mordents. However, during 
optimization, we also treated lyocell fabric in neutral and alkaline conditions without mordents, but we obtained better results using fixing agents. These results are in accordance with recently published work $[17,21]$. This may be due to the reason that alkaline conditions create more anionic fiber and dye molecules, resulting in the repulsion of dyes with poor color strength.

\subsection{Colorfastness properties of dyed lyocell fabrics}

\subsubsection{Washing fastness}

Figure 3 shows the outcomes of the washing fastness of the dyed lyocell fabric samples. The standard ISO 105-C03 was used for the washing fastness results. The figure explained that the mordanting agent, ferrous sulfate, has the utmost value of washing fastness at post-mordanting method. Similarly, the mordant potash dichromate has better staining effects with the post-mordanting method. However, the trend was different for agents such as copper sulfate and stannous chloride. They have better results in pre-mordanting method for most of the staining. It could also be perceived that all the staining in potash alum has similar and equal effective results in both mordanting methods. All the mordanting agents in both mordanting methods have good to excellent grade (4-5). Therefore, all the dyed samples have shown a slight change in color (4-5).

\subsubsection{Lightfastness}

Figure 4 shows the results of the lightfastness of dyed lyocell fabric in two mordanting methods. The standard ISO 105-B02 was used for the light fastness results. It has been observed that the light fastness with mordant ferrous sulfate in both mordanting methods has better results than with the other mordanting agents that were under study. Moreover, the ferrous sulfate in the post-mordanting method has superior effects ( 6 values) than the pre-mordanting method (5 values). The other three mordanting agents (potash dichromate, copper sulfate, and stannous chloride) have an identical effect (4 values) in color shade with both mordanting methods. It means for using these three mordants any mordanting method could be used. The mordant potash alum has the least effect (3 values) among

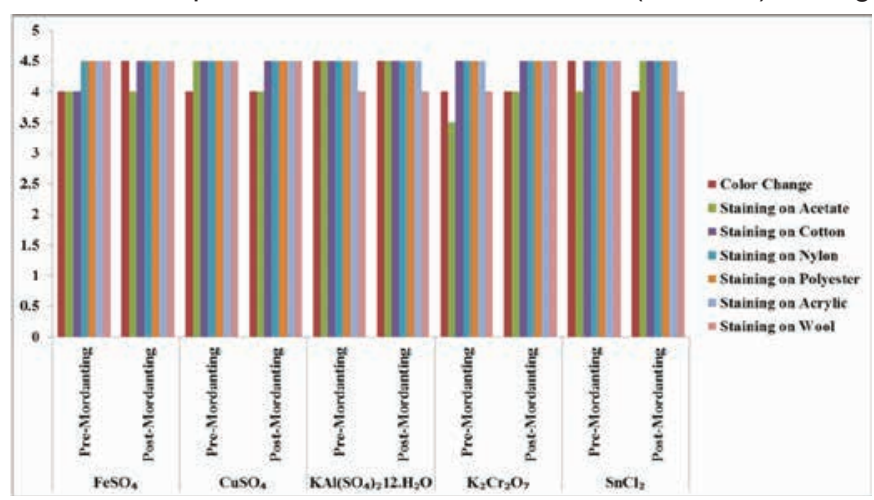

Figure 3. Washing fastness results of dyed lyocell fabric.

Table 1. Samples of dyed lyocell fabrics

\begin{tabular}{|c|c|c|c|c|c|}
\hline $\begin{array}{l}\text { Methods of } \\
\text { mordanting }\end{array}$ & $\mathrm{FeSO}_{4}$ & $\mathrm{CuSO}_{4}$ & $\mathrm{SnCl}_{2}$ & $\mathrm{~K}_{2} \mathrm{Cr}_{2} \mathrm{O}_{7}$ & $\mathrm{KAI}\left(\mathrm{SO}_{4}\right)_{2} 12 \cdot \mathrm{H}_{2} \mathrm{O}$ \\
\hline Pre-mordanting & & & & & \\
\hline Post-mordanting & & & & & \\
\hline
\end{tabular}

Table 2. CIE $L^{*} a^{*} b^{*} C^{*} h^{*}$, and $K / S$ values of dyed lyocell fabric

\begin{tabular}{|c|c|c|c|c|c|c|c|}
\hline Mordanting agent & $\begin{array}{c}\text { Mordanting } \\
\mathbf{m M e t h o d}\end{array}$ & $\mathbf{K} / \mathbf{S}$ & $\mathbf{L}^{*}$ & $\mathbf{a}^{*}$ & $\mathbf{b}^{*}$ & $\mathbf{c}^{*}$ & $\mathbf{h}^{*}$ \\
\hline $\mathrm{FeSO}_{4}$ & Pre-mordanting & 6.395 & --22.62 & 14.24 & 38.48 & 40.72 & --5.03 \\
\hline $\mathrm{FeSO}_{4}$ & Post-mordanting & 7.812 & --22.72 & 15.13 & 42.40 & 44.72 & --5.16 \\
\hline $\mathrm{Sncl}_{2}$ & Pre-mordanting & 1.057 & --4.68 & 1.76 & 17.92 & 17.94 & --1.49 \\
\hline $\mathrm{Sncl}_{2}$ & Post-mordanting & 1.314 & --2.23 & --0.13 & 13.71 & 13.70 & --0.66 \\
\hline $\mathrm{CuSO}_{4}$ & Pre-mordanting & 0.846 & --13.62 & --0.26 & 10.00 & 9.99 & --0.47 \\
\hline $\mathrm{CuSO}_{4}$ & Post-mordanting & 0.301 & --3.78 & --4.33 & 3.38 & 4.92 & 2.46 \\
\hline $\mathrm{K}_{2} \mathrm{Cr}_{2} \mathrm{O}_{7}$ & Pre-mordanting & 4.495 & --30.68 & 12.13 & 22.49 & 25.05 & --5.00 \\
\hline $\mathrm{K}_{2} \mathrm{Cr}_{2} \mathrm{O}_{7}$ & Post-mordanting & 1.787 & --17.39 & 1.96 & 16.02 & 16.07 & --1.55 \\
\hline $\mathrm{KAl}\left(\mathrm{SO}_{4}\right)_{2} 12 . \mathrm{H}_{2} \mathrm{O}$ & Pre-mordanting & 0.261 & --3.00 & 0.04 & 4.53 & 4.52 & --0.37 \\
\hline $\mathrm{KAI}\left(\mathrm{SO}_{4}\right)_{2} 12 . \mathrm{H}_{2} \mathrm{O}$ & Post-mordanting & 0.247 & --2.73 & 0.12 & 4.60 & 4.58 & --0.43 \\
\hline
\end{tabular}




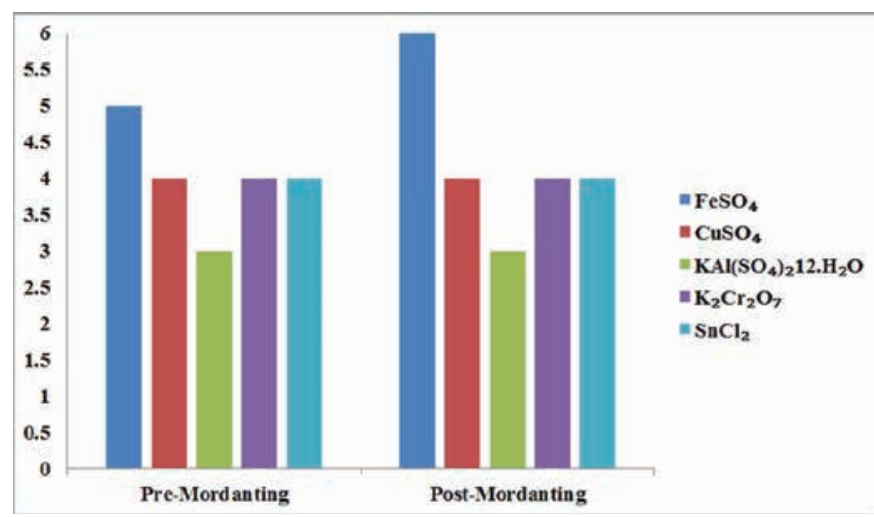

Figure 4. Lightfastness results of dyed lyocell fabric

all the mordanting agents in both methods. Both the mordanting methods have the similar effects. Thus, it is concluded from the figure that the mordant ferrous sulfate is the best choice for dyeing lyocell fabric by post-mordanting method.

\subsubsection{Rubbing (dry and wet) fastness}

Figure 5 illustrates the rubbing fastness results of dyed lyocell fabric (dry and wet) through the ISO standard (ISO 105-X12). The respective color bars have indicated the dry and wet rubbing test results of dyed fabric samples with ferrous sulfate, copper sulfate, potash alum, potash dichromate, and stannous chloride.

It was observed that the results of dry and wet rubbing fastness with most of the mordanting agents in post-mordanting method were better (4.5) than pre-mordanting method (4). Furthermore, in both mordanting methods, although there was a slight change in outcomes, the dry rubbing has effective results (4-4.5) than wet rubbing fastness (3.5-4). Thus, the respective bars of the ferrous sulfate, copper sulfate, and potash alum have shown good to excellent results, whereas the mordant potash dichromate gave the least rubbing fastness results (3-4).

\subsubsection{Perspiration (alkali and acidic) fastness}

Figure 6(a) and 6(b) shows the acidic and alkaline results of perspiration fastness of dyed lyocell fabric samples. The standard ISO-E04 was applied for test results. In Figure 6(a), the post-mordanting method has best and equal alkaline perspiration results with all mordanting agents, whereas premordanting method has a low effect through ferrous sulfate, potash dichromate, and stannous chloride in the case of staining on wool. The mordants, copper sulfate and potash alum, have similar effects in both mordanting methods. Thus, both can be used with any mordanting method.

In Figure 6(b), the respective bars have displayed that all mordanting agents have shown good to excellent results (44.5 ) in both mordanting methods. Furthermore, it was observed that post-mordanting method has better acidic perspiration effects through all mordanting agents except copper sulfate mordant (pre-mordanting method). The mordant potash alum has equal and similar effects in both mordanting methods. Mostly, the mordants have lower values with the last staining

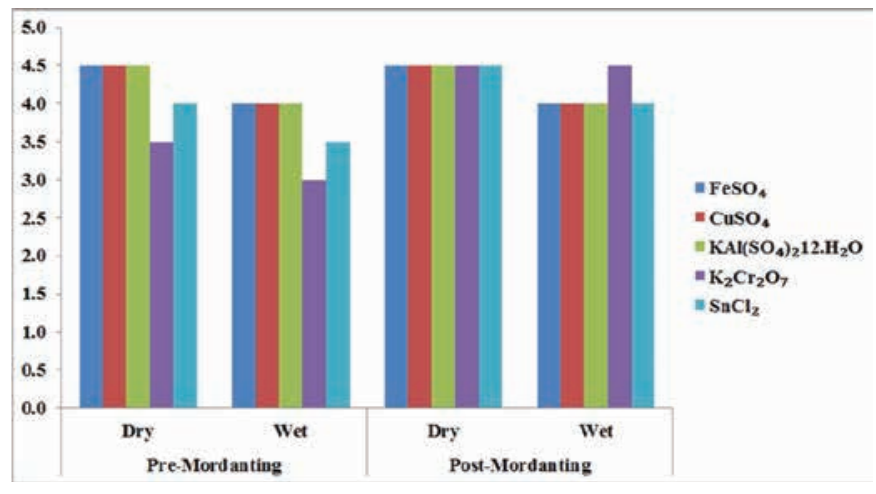

Figure 5. Rubbing fastness (Ddry and wet) of dyed lyocell fabric.

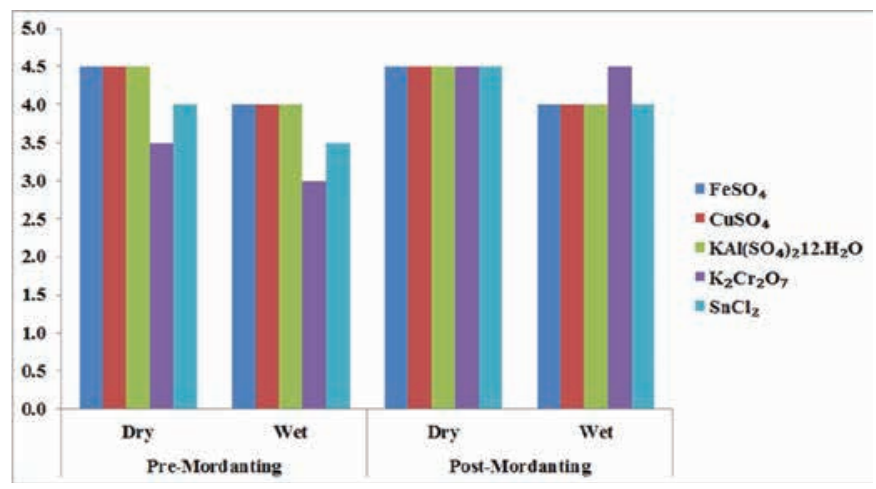

Figure 6(a). Acidic perspiration of dyed Lyocell fabric.

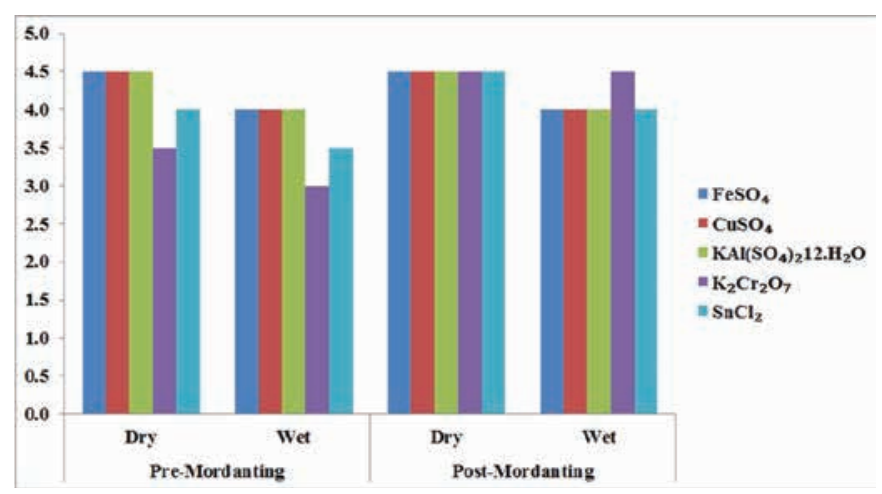

Figure 6(b). Alkali perspiration of dyed Lyocell fabric.

Figure 6. Acidic (a) and alkali (b) perspiration of dyed lyocell fabric

(staining on wool) because marigold flower dye also has substantively toward wool.

Figure 7 illustrates the Fourier transform infrared (FTIR) results of pre-mordanting and post-mordanting dyed samples. There was no structural change in pre- and post-mordanting methods and dyed fabrics. Moreover, it can be observed that there was no obvious structural change in dyed and un-dyed fabrics. The bands at $3444 \mathrm{~cm}^{-1}$ were due to $\mathrm{OH}$ group of cellulose. It was observed that peak elevations were increased after dyeing with such different mordants. Likewise, a vibration band at $2990 \mathrm{~cm}^{-1}$ has established the $\mathrm{CH}$ bending in all treated and untreated samples. In addition, all tested samples including 
dyed and un-dyed shown similar stretch peaks at $1369 \mathrm{~cm}^{-1}$ and $1312 \mathrm{~cm}^{-1}$ which confirmed the bending of $\mathrm{CH}$ and $\mathrm{CH}_{2}$ wagging, respectively. The vibration peak at $1150 \mathrm{~cm}^{-1}$ was due to the $\mathrm{C}-\mathrm{O}-\mathrm{C}$ stretching. Moreover, $1026 \mathrm{~cm}^{-1}$ presents the $\mathrm{C}-\mathrm{O}$ group of dyed and un-dyed lyocell fabrics. Besides, glucosides bonds at $845 \mathrm{~cm}^{-1}$ were also observed in all tested samples. The hydrophilicity of treated and un-treated lyocell has been shown in the fingerprint area at $710 \mathrm{~cm}^{-1}$ and $657 \mathrm{~cm}^{-1}$.

In the figures, overall, it could be observed that there were no significant differences in the structure of dyed and un-dyed lyocell fabrics except $\mathrm{OH}$ group of lyocell fabric was increased after dyeing. The presence of $\mathrm{OH}$ group was due to more hydrophilicity of cellulose. The results are also consistent with the literature [31].

\section{Conclusion}

In this study, the natural dye was successfully extracted from the Mexican marigold flower using a Soxhlet extraction apparatus. Five different mordanting agents, such as, ferrous sulfate, copper sulfate, potash alum, stannous chloride, and potash dichromate, were applied separately by pre-mordanting and post-mordanting methods for dye fixation. The experimental results revealed that the post-mordanting method has a slightly better effect than pre-mordanting method. Furthermore, the mordant ferrous sulfate was better in properties such as light fastness, washing fastness, and rubbing fastness by the postmordanting method. However, the perspiration fastness is equivalent with copper sulfate, stannous chloride, and potash alum and potash dichromate in both mordanting methods. Thus, the ferrous sulfate was a better choice for dyeing lyocell fabric by post-mordanting method since it has good color efficiency (K/S 7.812), and colorfastness to washing (4-5), rubbing (4-5), light (4-6), and perspiration (4-5). Thus, the dye extracted from the marigold flower shown good dyeing and colorfastness properties. Thus, a dye extracted from marigold flower may have a bright future because of its environmental safety and protection.

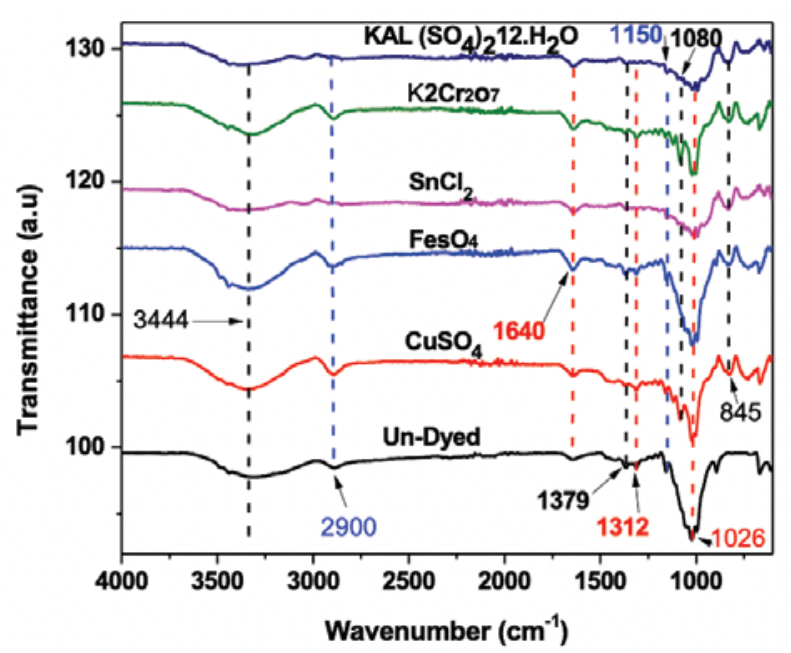

Figure 7. FTIR results of dyed lyocell fabric through post-mordanting method.

\section{Acknowledgments}

The research was supported by the Fundamental Research Funds for the Central Universities (No. 17D310503) and National Natural Foundation of China (No: 51403032).

\section{References}

[1] Prabhu, K., Bhute, A. S. (2012). Plant based natural dyes and mordants: A Review. Journal of Natural Product and Plant Resources, 2(6), 649-664.

[2] Kan, C. -W., Lo, C. K. Y., Man, W. S. (2016). Environmentally friendly aspects in coloration. Coloration Technology, 132(1), 4-8.

[3] Baaka, N., et al. (2017). Green dyeing process of modified cotton fibres using natural dyes extracted from Tamarix aphylla (L.) Karst. leaves. Natural Product Research, 31(1), 22-31.

[4] Sivakumar, V., Vijaeeswarri, J., Anna, J. L. (2011). Effective natural dye extraction from different plant materials using ultrasound. Industrial Crops and Products, 33(1), 116-122.

[5] Jha, C., et al. (2015). Extraction of natural dye from marigold flower (Tagetes erecta l.) and dyeing of fabric and yarns: A focus on colorimetric analysis and fastness properties. Der Pharmacia Lettre, 7(1), 185-195.

[6] Fossen, T., Cabrita, L., Andersen, O. M. (1998). Colour and stability of pure anthocyanins influenced by $\mathrm{pH}$ including the alkaline region. Food Chemistry, 63(4), 435-440.

[7] Calnan, C. (1976). Quinazoline yellow SS in cosmetics. Contact Dermatitis, 2(3), 160-166.

[8] Gao, L., Qian, X. (2002). Synthesis and photosensitizing properties of fluoroalkoxyl phthalocyanine metal complexes. Journal of Fluorine Chemistry, 113(2), 161165.

[9] Prasad, P. N., Williams, D.J. (1991). Introduction to nonlinear optical effects in molecules and polymers. Wiley.

[10] Savarino, P., Viscardi, G., Quagliotto, P., Montoneri, E., Barni, E. (1999). Reactivity and effects of cyclodextrins in textile dyeing. Dyes and Pigments, 42(2), 143-147.

[11] Kongkachuichay, P., Shitangkoon, A., Chinwongamorn, N. (2002). Thermodynamics of adsorption of laccaic acid on silk. Dyes and Pigments, 53(2), 179-185.

[12] Deo, H., Desai, B. (1999). Dyeing of cotton and jute with tea as a natural dye. Coloration Technology, 115(7-8), 224227.

[13] Mishra, S., Natural dyes with future aspects in dyeing of Textiles: A research article.

[14] Mahanta, D., Tiwari, S. (2005). Natural dye-yielding plants and indigenous knowledge on dye preparation in Arunachal Pradesh, northeast India. Current Science, 1474-1480.

[15] Ado, A., Yahaya, H., Kwalli, A. A., Abdulkadir, R. S. (2014). Dyeing of textiles with eco-friendly natural dyes: A review. International Journal of Environmental Monitoring and Assessment, 1(5), 76-81.

[16] Shetty, L. J., Sakr, F. M., Al-Obaidy, K., Patel, M. J., Shareef, H. (2015). A brief review on medicinal plant Tagetes erecta Linn A. Journal of Applied Pharmaceutical Science, 5(10), 091-095. 
[17] Adeel, S., Gulzarb, T., Azeem, M., Rehman, F., Saeed, M., et al. (2017). Appraisal of marigold flower based lutein as natural colourant for textile dyeing under the influence of gamma radiations. Radiation Physics and Chemistry, 130, 35-39.

[18] Velmurugan, P., Kim, J. I., Kim, K., Park, J. H., Lee, K. J., Chang, W. S., et al. (2017). Extraction of natural colorant from purple sweet potato and dyeing of fabrics with silver nanoparticles for augmented antibacterial activity against skin pathogens. J Photochem Photobiol B, 173, 571-579.

[19] Shabbir, M., Rather, L. J., Mohammad, F. (2018). Economically viable UV-protective and antioxidant finishing of wool fabric dyed with Tagetes erecta flower extract: Valorization of marigold. Industrial Crops and Products, 119, 277-282.

[20] Ding, Y., Freeman, H. S. (2017). Mordant dye application on cotton: optimisation and combination with natural dyes. Coloration Technology, 133(5), 369-375.

[21] Jothi, V., Walmiki, L. N., Goudar, G. (2017). Dyeing of cotton yarn with marigold (Tagetes erecta) petals: An emphasis on pre-treatments and mordants. Journal of Applied and Natural Science, 9(2), 1282

[22] Rehman, F., Adeel, S., Hanif, R., Muneer, M., Zia, K. M., et al. (2016). Modulation of Marigold Based Lutein Dye and its Dyeing Behaviour Using UV Radiation. Journal of Natural Fibers, 14(1), 63-70.

[23] Rehman, F., Naveed, T., Ullah, W, Pour, R. A. (2016). Extraction and Dyeing Behavior of Pomegranate dye on Tencel Fabric. Universal Journal of Environmental Research \& Technology, 6(4).

[24] Babar, A. A., Peerzada, M. H., Jhatial, A. K., Bughio, N. U. (2017). Pad ultrasonic batch dyeing of causticized lyocell fabric with reactive dyes. Ultrason Sonochem, 34, 993999.
[25] Taylor, J. (2015). Controlling fibrillation - experiences of the dyeing and finishing of lyocell fibres. Coloration Technology, 131(6), 424-433.

[26] Rehman, F., Sanbhal, N., Naveed, T., Farooq, A., Wang, $Y$. (2018). Antibacterial performance of Tencel fabric dyed with pomegranate peel extracted via ultrasonic method. Cellulose.

[27] Bhande, R., Giri, P. (2017). Extraction of Garcinia Indica Oil From Kokum Seed. International Journal of Engineering Technology, Management and Applied Sciences, 5, 724728.

[28] Toussirot, M., Nowikb, W., Hnawiaa, E., Lebouviera, N., Hay, A. -E. (2014). Dyeing properties, coloring compounds and antioxidant activity of Hubera nitidissima (Dunal) Chaowasku (Annonaceae). Dyes and Pigments, 102, 278284.

[29] Leon, K., Mery, D., Pedreschi, F., León, J. (2006). Color measurement in $L^{*} a{ }^{*} b$ * units from RGB digital images. Food Research International, 39(10), 1084-1091.

[30] Maha-In, K., Mongkholrattanasit, R., Klaichoi, C., Pimklang, W., Buathong, P., et al. (2016). Dyeing Silk Fabric with Natural Dye from Longan Leaves Using Simultaneous Mordanting Method. Materials Science Forum. Trans Tech Publ.

[31] Carrillo, F., Coloma, X., Suñolb, J. J., Saurinab, J. (2004). Structural FTIR analysis and thermal characterisation of lyocell and viscose-type fibres. European Polymer Journal, 40(9), 2229-2234. 